William A. Schiavone*, DO

\title{
Straight back syndrome as a clue to diagnosing asymptomatic congenital valvular heart disease and limiting the risk of weightlifting
}

https://doi.org/10.1515/jom-2020-0046

Received January 9, 2020; accepted July 12, 2020;

published online February 12, 2021

\begin{abstract}
Although both are initially asymptomatic, mitral valve prolapse/myxomatous mitral valve disease (MVP/MMVD) and bicuspid aortic valve (BAV), with its associated aortic disease, are currently the two most common congenital valvular heart diseases. Severe mitral regurgitation due to rupture of chordae tendineae (CTR) prompts surgery for MVP/MMVD. Surgery for BAV is performed for severe aortic stenosis and/or regurgitation, often with management of root and/or ascending aortic enlargement. There may be an association between straight back syndrome (SBS) and MVP/MMVD, which may be a key to earlier diagnosis. Other associations link weightlifting with ascending aortic enlargement and with CTR, where the common theme is blood pressure elevation. As the number of people with fitness center memberships continues to increase, this potentially exposes more undiagnosed individuals with MVP/MMVD or BAV to risk from weightlifting. Challenges include making the public aware of this risk and preparing the osteopathic physician to recognize patients at risk through a structured history-taking and targeted cardiovascular examination.
\end{abstract}

Keywords: aortic enlargement; BAV; MVP/MMVD; ruptured chordae tendineae; straight back syndrome; weightlifting.

The most common congenital valvular heart diseases are mitral valve prolapse/myxomatous mitral valve disease $(\mathrm{MVP} / \mathrm{MMVD})^{1}$ and bicuspid aortic valve (BAV), ${ }^{2}$ with its associated aortic disease. ${ }^{3}$ Although both diseases are largely initially asymptomatic, their combined estimated prevalence is $3-5 \%$ of the US population., ${ }^{1,2}$

*Corresponding author: William A. Schiavone, DO, Cleveland Clinic Heart and Vascular Institute (retired), 13705 Shaker Blvd, Apt 3A, Cleveland, OH 44120, USA, E-mail: schiavw@gmail.com
This disease prevalence explains why surgery for complications of MVP/MMVD has outnumbered surgery for rheumatic mitral valvular disease in developed nations since $1985,{ }^{4} 35$ years after the introduction of penicillin for streptococcal pharyngitis. It is the prevalence of BAV that allows its complications, including pure valvular disease and associated aortic enlargement to be relevant and important in the fields of open aortic valve and ascending aortic surgery. ${ }^{5}$

Chordae tendineae rupture ${ }^{6}$ and ascending aortic enlargement ${ }^{7}$ - complications in patients with MVP/MMVD and BAV - are directly related to hypertension. Highintensity weightlifting is known to increase blood pressure, ${ }^{8}$ which may increase the risk of developing these complications in susceptible individuals; connections between weightlifting and aortic aneurysm or dissection have been previously reported. ${ }^{9,10}$ A structured history and targeted cardiovascular physical designed for prospective weightlifters can aid physicians in the diagnosis of patients with asymptomatic congenital valve disease and allow them to steer these patients away from potentially harmful heavy weightlifting and, if appropriate, toward safer, more moderate weightlifting. ${ }^{8}$

\section{Clinical summary}

\section{Pathophysiology of complications of MVP/MMVD and BAV}

Myxomatous degeneration renders the mitral valve redundant; the chordae tendineae lengthen and strain forces exceed their capacity to stretch. This results in CTR under circumstances that would be tolerated by a normal mitral valve. The degree of resultant mitral regurgitation depends on the size and number of chordae tendineae ruptured, the chronicity, the left atrial size, and its ability to absorb the regurgitant volume, known as capacitance.

Unlike the leaflets of a normal tricuspid aortic valve that fold against the aortic root out of the flow of blood 
during systole, the BAV leaflets remain in the turbulent flow, will scar, and will have prematurely restricted motion. Joseph et $\mathrm{al}^{11}$ showed that asymmetry among aortic valve cusps, even those of tricuspid aortic valves, is strongly associated with the future development of aortic stenosis. The scenario of the BAV is different from that of senile tricuspid aortic stenosis because BAV disease occurs earlier and often involves the aortic root and/or ascending aorta. ${ }^{12}$ An enlarged aortic root or ascending aorta sustains increased wall stress which begets further aortic enlargement, dissection, or rupture.

\section{Observations and associations regarding MVP/MMVD and BAV at a cardiac surgical center}

Straight back syndrome (SBS), a particular skeletal back deformity defined by a vertical dorsal spine without the normal degree of dorsal kyphosis, is common in patients with MVP/MMVD (Figure 1). Osteopathic physicians' expertise in spinal examination makes them especially skilled at diagnosing SBS, ${ }^{13}$ which can lead to a diagnosis

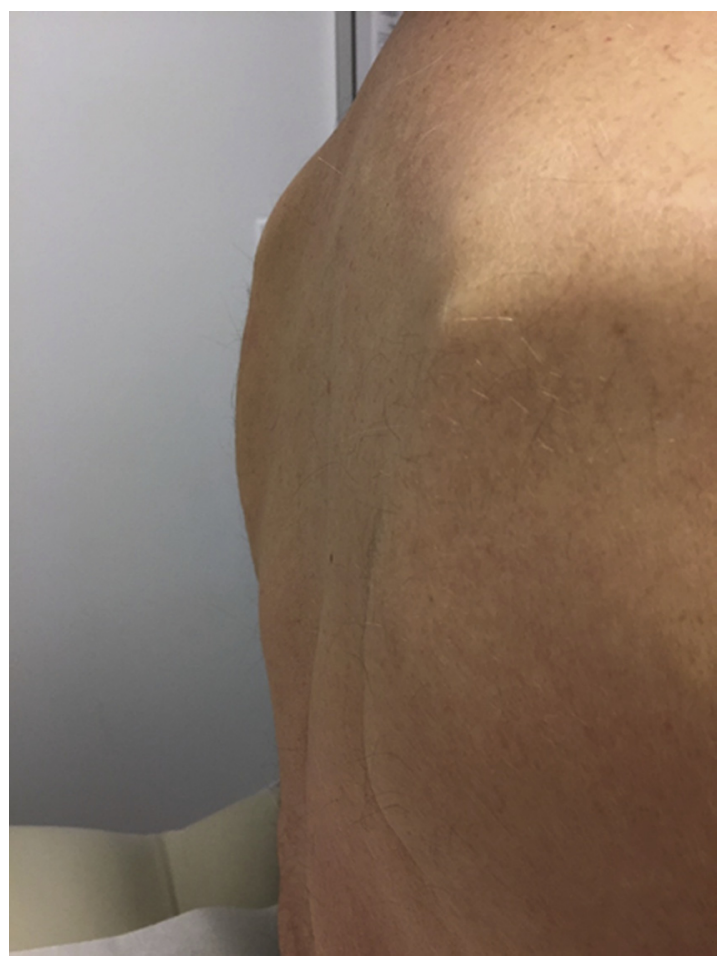

Figure 1: Photograph of a 61-year-old man with straight back syndrome (SBS) who has mitral valve prolapse/myxomatous mitral valve disease (MVP/MMVD). Notice the absence of normal dorsal kyphosis. of MVP/MMVD. According to the method described by Davies et $a l,{ }^{14}$ dorsal kyphosis curvature was measured by a perpendicular line (AP distance) drawn from the middle of the anterior border of $\mathrm{T} 8$ vertebral body to a vertical line connecting anterior superior $\mathrm{T} 4$ and anterior inferior $\mathrm{T} 12$ on a lateral chest radiograph. An AP distance of $<12 \mathrm{~mm}$ was defined as SBS (Figure 2). SBS was previously associated with MVP/MMVD, ${ }^{14-16}$ but it was not until 2017 that Movahed et $\mathrm{al}^{17}$ demonstrated a statistically-significant association. In fact, in that study, ${ }^{17}$ SBS was present in $27 \%$ of 75 patients who underwent mitral valve repair or replacement for severe mitral regurgitation due to MVP/ MMVD, compared to only $6.7 \%$ of 225 age-, sex-, and body mass index-matched patients without mitral valve disease who underwent coronary artery bypass surgery in the same 2-year period ( $\mathrm{p}<0.0001$; odds ratio, 5.1; 95\% CI, 2.4-10.6).

Very muscular young men who were weightlifters and were found to have BAV appeared to develop aortic root aneurysm and/or ascending aortic aneurysm with significant aortic regurgitation (AR) at an even younger age than

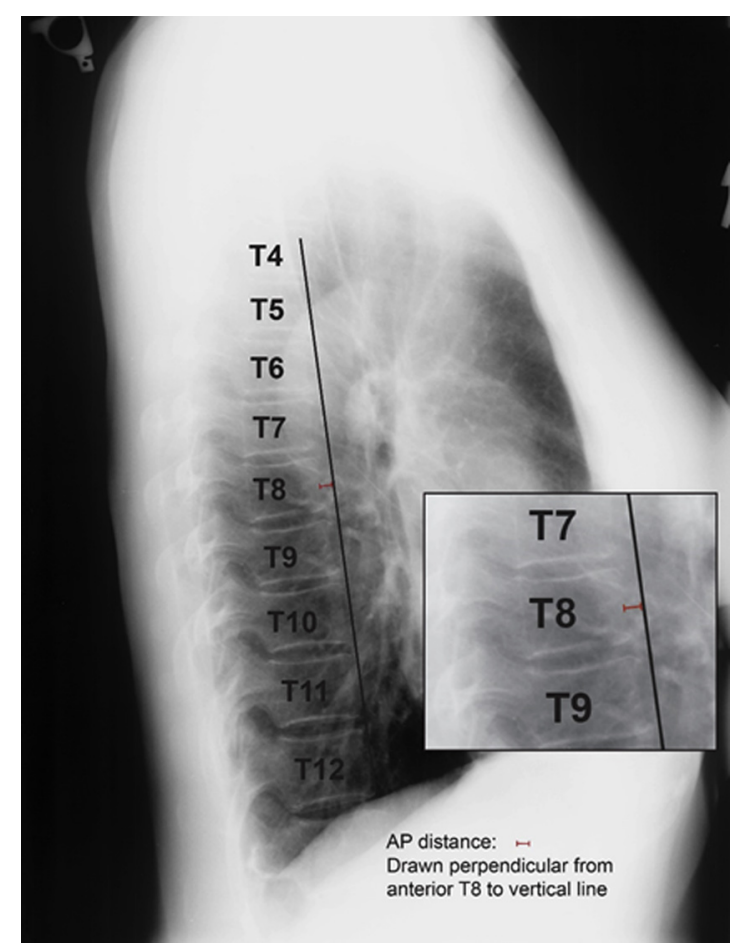

Figure 2: Lateral chest radiograph, with magnified insert in lower right, used to measure AP distance (red bar) in a 50-year-old woman with straight back syndrome (SBS) who has mitral valve prolapse/ myxomatous mitral valve disease (MVP/MMVD). Dorsal kyphosis curvature was measured from the length of a perpendicular line (called AP distance) drawn from the middle of the anterior border of T8 vertebral body to a vertical line connecting anterior superior T4 and anterior inferior T12 on a lateral chest radiograph. AP distance $<12 \mathrm{~mm}$ is defined as straight back. 
anticipated. In 1991, Levinson and Southern ${ }^{9}$ reported a case of a 33-year-old man with BAV and made this very same weightlifting, ascending aortic dilatation, and AR association at a time when BAV had not yet been closely linked to the propensity for aortic dilatation.

Several middle-aged and older men trying to improve their physical fitness by weightlifting have presented for repair of severe mitral regurgitation, some of whom stated that they remembered feeling a pop in the chest while weightlifting, which was the start of their dyspnea. At surgical repair, all of these individuals had MVP/MMVD and at least one ruptured chorda tendinea (based on the author's clinical experience).

\section{Increase in blood pressure: a common theme in failure of MVP/MMVD and BAV}

The common theme - in both the young, muscular weightlifters with BAV who developed premature aortic aneurysm and also the middle-aged and older men trying to improve their physical fitness by weightlifting who had MVP/MMVD and developed dyspnea due to ruptured mitral chordae tendineae - was temporary blood pressure (BP) elevation caused by heavy weightlifting. When bench pressing heavy weight, BP can rise to dangerous levels of $300 / 150 \mathrm{mmHg}$ or more (personal observation), but less impressive BP elevations, repeated over time, may also be impactful.

\section{Factors contributing to blood pressure increase during weightlifting}

Arterial BP increases most during weightlifting that is accompanied by mechanical compression of blood vessels (such as when bent forward at the waist or squatting) and when accompanied by a Valsalva maneuver. ${ }^{18}$ It increases more when weightlifting is done as a set of repetitions to failure, compared to the $\mathrm{BP}$ response when weightlifting is done as a single maximal effort. ${ }^{19}$ Palatini et al concluded that pronounced increases in intra-thoracic and intra-abdominal pressures are major determinants of blood pressure elevation during weightlifting. ${ }^{20}$

\section{Bicuspid aortic valve, hypertension, and ascending aortic enlargement}

Roberts ${ }^{21}$ reported in 1989 that patients with a BAV should discontinue lifting weights because this type of exercise puts undue stress (i.e., pressure), although for short periods, on the aortic valve. Women with Turner Syndrome who had BAV were found to have a greater ascending aortic diameter when they had hypertension, even in the absence of aortic coarctation. ${ }^{7}$ In another study, ${ }^{10}$ weightliftingrelated acute aortic dissection appeared to be a real phenomenon and moderate aortic dilatation was deemed to confer vulnerability to exertion-related aortic dissection.

\section{Analysis of survivors of aortic dissection}

Among 197 patients from a single academic institution who survived surgical repair of aortic dissection between 1996 and 2011, 82 (42\%) completed a survey regarding their status on the day the acute dissection occurred. ${ }^{22}$ The survey revealed that $60 \%$ had hypertension, $17 \%$ did not exercise, and $15 \%$ did weightlifting. ${ }^{22}$ Among the same 82 survey respondents, the five most common exercise goals were to live longer (70\%), to improve heart health (62\%), to lose fat (50\%), to be stronger (41\%), and to have a lower resting heart rate and blood pressure (39\%). ${ }^{22}$ Only $4 \%$ of the respondents reported "bigger muscles" as the goal. ${ }^{22}$

\section{Strong association of MVP/MMVD, hypertension, and chordal rupture}

Since 1985, when MVP/MMVD became more common than rheumatic mitral valve disease in developed nations, it has been the etiology that accounts for the majority of CTR. ${ }^{4}$ In 2009, a study by Taiwanese researchers ${ }^{6}$ included 494 patients with CTR of which 351 patients (71\%) had idiopathic CTR, which was largely composed of patients with MVP/MMVD. The authors concluded that there was a strong association between preexisting hypertension and idiopathic CTR. ${ }^{6}$ In 1990, Cheng $^{23}$ agreed with the guidelines proposed by Roberts for BAV - namely, that patients with MVP/MMVD should not be weightlifters.

\section{The burden of BAV and of MVP/MMVD}

Bicuspid aortic valve (BAV) is the most common congenital cardiac abnormality in the general population with a prevalence of $1-2 \%$, and it is almost three times more common in men than in women. ${ }^{2} \mathrm{MVP} / \mathrm{MMVD}$ is a common disorder that afflicts $2-3 \%$ of the general population. ${ }^{1}$ These, the two most common congenital cardiac abnormalities, can be asymptomatic until dangerous aortic root or ascending aortic enlargement or rupture occurs or until chordae tendineae rupture occurs. It is fortunate, however, that family history can be a guide and that a physical 
examination which includes measurement of BP, inspection of the dorsal spine for SBS, and cardiac auscultation can often identify a patient with BAV or MVP/MMVD before a significant problem develops.

\section{The growth of fitness center and health club membership}

The total number of memberships at fitness centers and health clubs in the United States (US) from 2000 to 2017 increased from 32.8 million to 60.9 million. ${ }^{24}$ In this time of increasing obesity in the US, an increasing number of businesses are financing such memberships for their employees. ${ }^{25}$

Extrapolating from these figures and the estimated prevalence of each condition, the approximate number of fitness center and health club members in the US in 2017 who have BAV could be estimated in a range of 0.609-1.218 million, and the approximate number of members who have MVP/MMVD could be from 1.218 to 1.827 million. The approximate number of members who have either BAV or MVP/MMVD could range from 1.827 to 3.045 million.

Using the data from Chaddha et $\mathrm{al}^{22}$ to assume that $4 \%$ of these members with BAV or MVP/MMVD seriously lift weights with the goal of "having bigger muscles" (presumed heavy lifting) and in so doing raise their BP, there could be between 72,120 and 120,200 people who risk provoking either aortic enlargement/aneurysm or dissection, or ruptured mitral chordae tendineae.

\section{Challenges and goals}

Two challenges and goals have been identified. First, to prevent some weightlifters from doing harm, it is important to make this heavy weightlifting and silent valvular heart disease association known to the public prior to their engaging in such activity. Second, it is important to provide a clear and comprehensive path connecting medical professionals capable of conducting a full history and physical examination with patients potentially at risk, so they can provide counsel prior to patients engaging in heavy weightlifting.

\section{Recommendations for fitness centers, health clubs, and professional medical organizations}

I recommend that fitness centers, health clubs, and professional medical organizations notify their members and the public via the press, social media, and other outlets that: (1) due to silent and undiagnosed valvular heart diseases in 3-5\% of people, heavy weightlifting can be harmful; (2) every prospective weightlifter should investigate family history for BAV and MVP/MMVD; and (3) every prospective weightlifter should visit a medical provider who has interest and skill in physical examination, including spinal examination and cardiac auscultation.

\section{Recommendations for the medical provider examining prospective weightlifters}

I recommend that medical providers perform a physical examination of a prospective weightlifter to investigate for family history of BAV, MVP/MMVD, or valve or aortic surgery. The physical examination should include an assessment for hypertension; an inspection for absence of dorsal kyphosis (straight back; Figures 1 and 2); auscultation for ejection click (BAV), heard best at apex in left lateral recumbent position (LLRP), and for murmur of aortic regurgitation (AR) or aortic stenosis (AS), heard best at base; and auscultation for mid-systolic click (MVP/MMVD), heard best at left lower sternal border in LLRP, and for mitral regurgitation (MR) murmur, heard best at apex. A checklist reviewing a prospective weightlifter's family history and physical examination should be completed (Table 1). The patient's categorization and clinical recommendations (if applicable) resulting from the family history and physical examination should then be reviewed (Table 2).

\section{Recommendations based on results of history and physical for prospective weightlifters}

Table 2 contains a summary of recommendations based on the results of family history review and physical examination. With experience, normal cardiac auscultation (the absence of an abnormal click or murmur) is more reliable than identifying the source of an abnormal click. The source of an early systolic click is often difficult to identify as coming from BAV ejection click or from split first heart sound. ${ }^{26}$ That is why Doppler echocardiography, ordered with the specific question to be answered, is recommended when the results of auscultation are positive or equivocal. ${ }^{26}$ In this way, individuals with normal results are quickly screened and cleared, and those with BAV (with or without aortic disease) and those with MVP/MMVP are confidently identified before labeling them with a disease and restricting their activity. 
Table 1: Checklist for family history and physical examination for prospective weightlifters.

Present Absent

Family history for BAV, ascending aortic aneurysm,

MVP/MMVD or surgery for valvular or aortic disease

Assessment for hypertension

Inspection for straight back syndrome

Auscultation for BAV (systolic ejection click,

systolic murmur of AS or diastolic murmur of AR)

Auscultation for MVP/MMVD (mid-systolic click

and/or systolic murmur of MR)

$A R$, aortic regurgitation; $A S$, aortic stenosis; $B A V$, bicuspid aortic valve; $M V P / M M V D$, mitral valve prolapse/myxomatous mitral valve disease.

Table 2: Categories, results, and recommendations after family history and physical examination for prospective weightlifters.

\begin{tabular}{|c|c|c|}
\hline Category & Result & Recommendation \\
\hline tegory 1 & $\begin{array}{l}\text { Family history: Absent } \\
\text { Hypertension: Absent } \\
\text { Straight back: Absent } \\
\text { Auscultation findings for } \\
\text { BAV: Absent } \\
\text { Auscultation findings for } \\
\text { MVP/MMVD: Absent }\end{array}$ & $\begin{array}{l}\text { Advise that there is no his- } \\
\text { tory and physical reason to } \\
\text { avoid weightlifting }\end{array}$ \\
\hline Category 2 & Hypertension: Present & $\begin{array}{l}\text { Advise that weightlifting be } \\
\text { deferred until hypertension } \\
\text { is rechecked; if persistent, it } \\
\text { should be appropriately } \\
\text { treated }\end{array}$ \\
\hline Category 3 & $\begin{array}{l}\text { Family history of BAV, } \\
\text { aortic aneurysm, MVP/ } \\
\text { MMVD or related sur- } \\
\text { gery: Present }\end{array}$ & $\begin{array}{l}\text { Advise that weightlifting be } \\
\text { deferred and refer for } \\
\text { Doppler echocardiography } \\
\text { requesting clarification of }\end{array}$ \\
\hline Category 4 & $\begin{array}{l}\text { Straight back syndrome: } \\
\text { Present }\end{array}$ & $\begin{array}{l}\text { the category(ies) that are } \\
\text { checked }\end{array}$ \\
\hline Category 5 & $\begin{array}{l}\text { Auscultation findings for } \\
\text { BAV: Present }\end{array}$ & \\
\hline Category 6 & $\begin{array}{l}\text { Auscultation findings for } \\
\text { MVP/MMVD: Present }\end{array}$ & \\
\hline
\end{tabular}

BAV, bicuspid aortic valve; MVP/MMVD, mitral valve prolapse/ myxomatous mitral valve disease.

\section{Recommended management of results of the Doppler echocardiogram for categories 3-6}

If $\mathrm{BAV}$, aortic root or ascending aortic enlargement, AS and/or AR, MVP/MMVD, or MR is identified, advise the prospective weightlifter not to lift weights and be evaluated by a cardiologist. If none of the anticipated abnormalities is identified by Doppler echocardiography, reexamine the patient and decide whether clearance for weightlifting be given. If still in doubt, another follow-up examination or cardiology consultation is warranted.

\section{Discussion}

The association of MVP/MMVD with SBS is important because the osteopathic physician skilled at diagnosing SBS may be more likely to note the presence of MVP/MMVD and therefore be able to make the diagnosis even before there is a murmur, potentially preventing a complication resulting from weightlifting. In addition, the symptoms of SBS outlined by Gold et al, ${ }^{13}$ midthoracic pain and tightness, were effectively treated with spinal manipulation. In this same case report, ${ }^{13}$ the associated cervical lordotic reversal at C4-5 with mild joint/foraminal narrowing, a compensation for the loss of dorsal kyphosis, might account for the symptoms of shortness of breath in the absence of heart or lung disease and be due to compromised phrenic nerve innervation of the diaphragm. Movahed et $\mathrm{al}^{17}$ also found that patients with MVP/MMVD requiring mitral valve surgery who also had SBS more commonly had a history of cervical fusion. Appropriate thoracic and cervical manipulation followed by prescribed daily exercise and stretching appear to have preventive roles here.

Examining the thoracic cage has long been a strength of the osteopathic physician. Deformities such as pectus excavatum, pectus carinatum, hemi-pectus carinatum, and dorsal lordosis and their association with Marfan syndrome and cardiovascular disease were described in the osteopathic literature in $1990^{27}$ and pectus excavatum was reviewed in $2017 .^{28}$

\section{Conclusion}

While the associations and observations presented in this Clinical Practice report are based on cases referred to a cardiac surgery center rather than on randomized controlled trials (RCT), they are supported by similar observations from the literature, cited here, some of which include published guidelines. Understanding the pathophysiology of MVP/ MMVD CTR, aortic root and ascending aortic enlargement and AR with BAV, and how they are linked with hypertension - which can be provoked by heavy weightlifting - is important in order for osteopathic physicians to deliver high-quality care to patients with these diseases, since osteopathic physicians will frequently see prospective weightlifters in their practices. An RCT will hopefully be developed and published in the osteopathic medical 
literature in the future to further prove the practical or preventive value of this checklist beyond its theoretical value.

Research funding: None declared.

Author contributions: The author provided substantial contributions to conception and design, acquisition of data, or analysis and interpretation of data; the author drafted the article or revised it critically for important intellectual content; the author gave final approval of the version of the article to be published; and the author agrees to be accountable for all aspects of the work in ensuring that questions related to the accuracy or integrity of any part of the work are appropriately investigated and resolved.

Competing interests: The author is the founder of EKGaction.com, an educational website.

\section{References}

1. Delling FN, Vasan RS. Epidemiology and pathophysiology of mitral valve prolapse: new insights into disease progression, genetics, and molecular basis. Circulation, 2014;129(21):2158-2170. doi: 10. 1161/CIRCULATIONAHA.113.006702

2. Mordi I, Tzemos N. Bicuspid aortic valve disease: a comprehensive review. Cardiol Res Pract. 2012;2012:196037. doi: 10.1155/2012/ 196037

3. Braverman AC. Aortic involvement in patients with a bicuspid aortic valve. Heart. 2011;97(6):506-513. doi: 10.1136/hrt.2009. 183871

4. Gabbay U, Yosefy C. The underlying causes of chordae tendinae rupture: a systemic review. Int J Cardiol, 2010;143(2):113-118.

5. Borger MA, Fedak PWM, Stephens EH, et al. The American Association for Thoracic Surgery consensus guidelines on bicuspid aortic valve-related aortopathy: full online-only version. J Thorac Cardiovasc Surg. 2018;156(2):e41-e74. doi: 10.1016/j. jtcvs.2018.02.115

6. Juang JJ, Ke SR, Lin JL, et al. Rupture of mitral chordae tendineae: adding to the list of hypertension complications. Heart. 2009; 95(12):976-979. doi: 10.1136/hrt.2008.159848

7. Hjerrild BE, Mortensen KH, Sorensen KE, et al. Thoracic aortopathy in Turner syndrome and the influence of bicuspid aortic valves and blood pressure: a CMR study. J Cardiovasc Magn Reson. 2010; 12(1):12. doi: 10.1186/1532-429X-12-12

8. Williams MA, Haskell WL, Ades PA, et al. Resistance exercise in individuals with and without cardiovascular disease: 2007 update; a scientific statement from the American Heart Association Council on Clinical Cardiology and Council on Nutrition, Physical Activity, and Metabolism. Circulation. 2007;116(5):572-584 doi: 10.1161/ CIRCULATIONAHA.107.185214

9. Levinson JR, Southern JF. Case Records of the Massachusetts General Hospital. Weekly clinicopathological exercises. Case 381991. A 33-year-old man with dilatation of the ascending aorta and aortic regurgitation. N Engl J Med. 1991;325(12):874-882. doi: 10. 1056/NEJM199109193251208
10. Hatzaras I, Tranquilli M, Coady M, Barrett PM, Bible J, Elefteriades JA. Weight lifting and aortic dissection: more evidence for a connection. Cardiology. 2007;107(2):103-106. doi: 10.1159/000094530

11. Joseph L, Krishnaswamy A, Tuzcu EM, et al. Relation of cuspal asymmetry to development of aortic stenosis in adults with tricuspid aortic valves. J Heart Valve Dis. 2014;23(4):395-405.

12. Lindman BR, Clavel MA, Mathieu P, et al. Calcific aortic stenosis. Nat Rev Dis Primers. 2016;2:16006. doi: 10.1038/nrdp.2016.6

13. Gold PM, Albright B, Anani S, Toner H. Straight back syndrome: positive response to spinal manipulation and adjunctive therapy - $\mathrm{a}$ case report. J Can Chiropr Assoc. 2013;57(2):143-149.

14. Davies MK, Mackintosh P, Cayton RM, Page AJ, Shiu MF, Littler WA. The straight back syndrome. Q J Med. 1980;49:443-460.

15. Serratto M, Kezdi P. Absence of the physiologic dorsal kyphosis. Cardiac signs and hemodynamic manifestations. Ann Intern Med. 1963;58:938-945. doi: 10.7326/0003-4819-58-6-938

16. Soleti P, Wilson B, Vijayakumar AR, Chakravarthi PIS, Reddy CG. An interesting case of straight back syndrome and review of the literature. Asian Cardiovasc Thorac Ann. 2016;24(1):63-65. doi: 10.1177/0218492314539335

17. Movahed A, Majdalany D, Gillinov M, Schiavone W. Association between myxomatous mitral valve disease and skeletal back deformities. J Heart Valve Dis. 2017;26(5):564-568.

18. MacDougall JD, Tuxen D, Sale DG, Moroz JR, Sutton JR. Arterial blood pressure response to heavy resistance exercise. J Appl Physiol. 1985;58(3):785-790. doi: 10.1152/jappl.1985.58.3.785

19. Sale DG, Moroz DE, McKelvie RS, MacDougall JD, McCartney N. Comparison of blood pressure response to isokinetic and weightlifting exercise. Eur J Appl Physiol Occup Physiol. 1993;67(2): 115-120. doi: 10.1007/BF00376653

20. Palatini P, Mos L, Munari L, et al. Blood pressure changes during heavy-resistance exercise. J Hypertens Suppl. 1989;7(6): S72-S73. doi: 10.1097/00004872-198900076-00032

21. Roberts WC. Living with a congenitally bicuspid aortic valve. $A m$ J Cardiol. 1989;64:1408-1409. doi: 10.1016/0002-9149(89)90598-5

22. Chaddha A, Kline-Rogers E, Braverman AC, et al. Survivors of aortic dissection: activity, mental health, and sexual function. Clinical Cardiol. 2015;38(11):652-659. doi: 10.1002/clc. 22418

23. Cheng TO. Living with mitral valve prolapse. Am J Cardiol. 1990; 66(4):528. doi: 10.1016/0002-9149(90)90723-e

24. Gough C. Total number of memberships at fitness centers/health clubs in the US from 2000 to 2017 (in millions). Accessed 9 Jan 2020. https://www.statista.com/statistics/236123/us-fitnesscenter-health-club-memberships/

25. Midgley $B$. The six reasons the fitness industry is booming. Accessed January 9, 2020. www.forbes.com/sites/benmidgley/ 2018/09/26/the-six-reasons-the-fitness-industry-is-booming/ \#5aaa19f1506d

26. Hoeting NM, McCracken CE, McConnell M, Sallee D, lannucci GJ, Oster ME. Systolic ejection click versus split first heart sound: are our ears deceiving us? Congenit Heart Dis. 2017;12(4):417-420. doi: $10.1111 /$ chd. 12460

27. Obarski TP, Schiavone WA. Thoracic cage deformities in the early diagnosis of the Marfan syndrome and cardiovascular disease. J Am Osteopath Assoc. 1990;90(5):446-450.

28. Abid I, Ewais MM, Marranca J, Jaroszewski DE. Pectus excavatum: a review of diagnosis and current treatment options. J Am Osteopath Assoc. 2017;117(2):106-113. doi: 10.7556/jaoa.2017.021 